\title{
Industrial gassing poisonings due to trichlorethylene, perchlorethylene, and 1-1-1 trichloroethane, 1961-80
}

\author{
T B McCARTHY AND R D JONES \\ From Health and Safety Executive, London W2 4TF, UK
}

ABSTRACT During the period 1961-80, 384 cases of industrial gassing poisonings by trichlorethylene, perchlorethylene, and 1-1-1 trichloroethane (methylchloroform) were reported to HM Factory Inspectorate. A study of these data, which have been collated and analysed with particular reference to sex, age, clinical manifestations, and circumstances of the incident, is presented. Possible bias of the data owing to its source and method of extraction is discussed. The study shows the hazards inherent in the use of these narcotic solvents and discusses the circumstances that appear most likely to produce problems. The vulnerability of the younger worker is shown. Toxic effects were most commonly exerted on the central nervous system but no good evidence of cardiac or hepatic toxicity was found. In nine cases evidence of deliberate sniffing of solvent was reported. The problem of solvent abuse in an industrial context is discussed.

Chlorinated hydrocarbon solvents have been used extensively over the past 100 years as degreasing agents. In sufficient concentration they cause depression of the central nervous system, and some have found use as anaesthetic agents. ${ }^{12}$ Untoward toxic effects have occurred as a result of their use in industry, probably the most dramatic being those produced by tetrachloroethane. ${ }^{34}$ All the commonly used chlorinated hydrocarbon solvents have anaesthetic properties and some members of the group exhibit additional toxic effects. Peripheral neuropathy has been described in association with tetrachloroethane exposure ${ }^{5}$ and some of these compounds have been shown to cause liver damage and cardiac arrhythmias. ${ }^{36-8}$ Renal damage has also been reported..$^{79}$ Because of these toxic properties some of these solvents are now seldom used and have been replaced by similar compounds that are generally considered less toxic. Probably the three most commonly used chlorinated hydrocarbon solvents in industry today are trichlorethylene, perchlorethylene, and 1-1-1 trichloroethane. The use of these substances is extremely widespread. The toxic hazards posed by the industrial use of these socalled safer chlorinated hydrocarbon solvents has been the subject of much discussion and review for several years. ${ }^{11-13}$ The medical records of cases of industrial gassings reported to HM Factory Inspec-

Received 22 November 1982

Accepted 20 December 1982 torate have not been reviewed since Browning's excellent text book on toxicity of industrial solvents was published in $1965 .{ }^{14}$ It was therefore decided to review those cases attributed to one or other of these three common solvents reported in the period 1961-80 to provide further information on some of the issues still under debate. Whereas questions such as hepatotoxicity were of particular interest, a complete analysis of the available data has been attempted for the first time.

\section{Data source}

Under section 80 of the Factories Act any accident was notifiable if it caused loss of life to a person employed in premises subject to that Act or if it disabled any such person for more than three days from earning full wages at the work in which he was employed. ${ }^{15}$ Cases were notifiable to HM Inspector responsible for that area who, in the case of a gassing accident, then informed the employment medical adviser (before 1973 this would have been an appointed factory doctor or medical inspector of factories). This medical officer then reported on the medical aspects of the case, a copy of his report being sent to the Employment Medical Advisory Service head office for retention. In some of these cases it may have been subsequently found that the circumstances of the incident did not meet the 
statutory requirements for notification under the Act. For the purposes of this study, however, we have used the medical reports on all the cases where poisoning due to one of these solvents apparently occurred. Thus the figures here may exceed the notifiable incidents published by HM Factory Inspectorate.

\section{Method}

Before starting to examine the records, a list of specific items to be searched for was drawn up. Each individual report from 1961-80 was then scrutinised and for all records the following data were extracted: age, sex, occupation, process and industry, date of occurrence, and whether or not fatal. Clinical findings were divided into six categorieseffects on the central nervous, respiratory, cardiovascular, hepatic, gastrointestinal, and renal systems. The degree of severity of narcotic effects in each case was assessed from the record on the following basis. Where specific mention of unconsciousness was made, the case was accepted as belonging to the more severe group. Cases where consciousness was preserved, or mention of so- called semiconsciousness or stupor was made, were classified as less severe cases. The mode of use of the solvents were classified according to whether: (1) the solvent was being used in a fixed tank installation, (2) maintenance of fixed tank installation was being carried out, (3) solvent was being used in portable form-that is, bucket solvent, (4) solvent was being used for dry cleaning process, or (5) other miscellaneous circumstances.

Because of certain aspects of the data discovered during the analysis a specific search for mention of addiction was added to the criteria decided on a priori.

\section{Results}

For 1961-80 inclusive, 330 gassing incidents involving these solvents were reported, affecting 384 people: 288 were affected by trichlorethylene, 44 by perchlorethylene, and 52 by 1-1-1 trichloroethane. Seventeen cases were fatal and of the remaining 367,168 were sufficiently severe to result in unconsciousness. Trichlorethylene was responsible for 12 deaths, perchlorethylene for three, and 1-1-1 trichloroethane for the remaining two. The number of

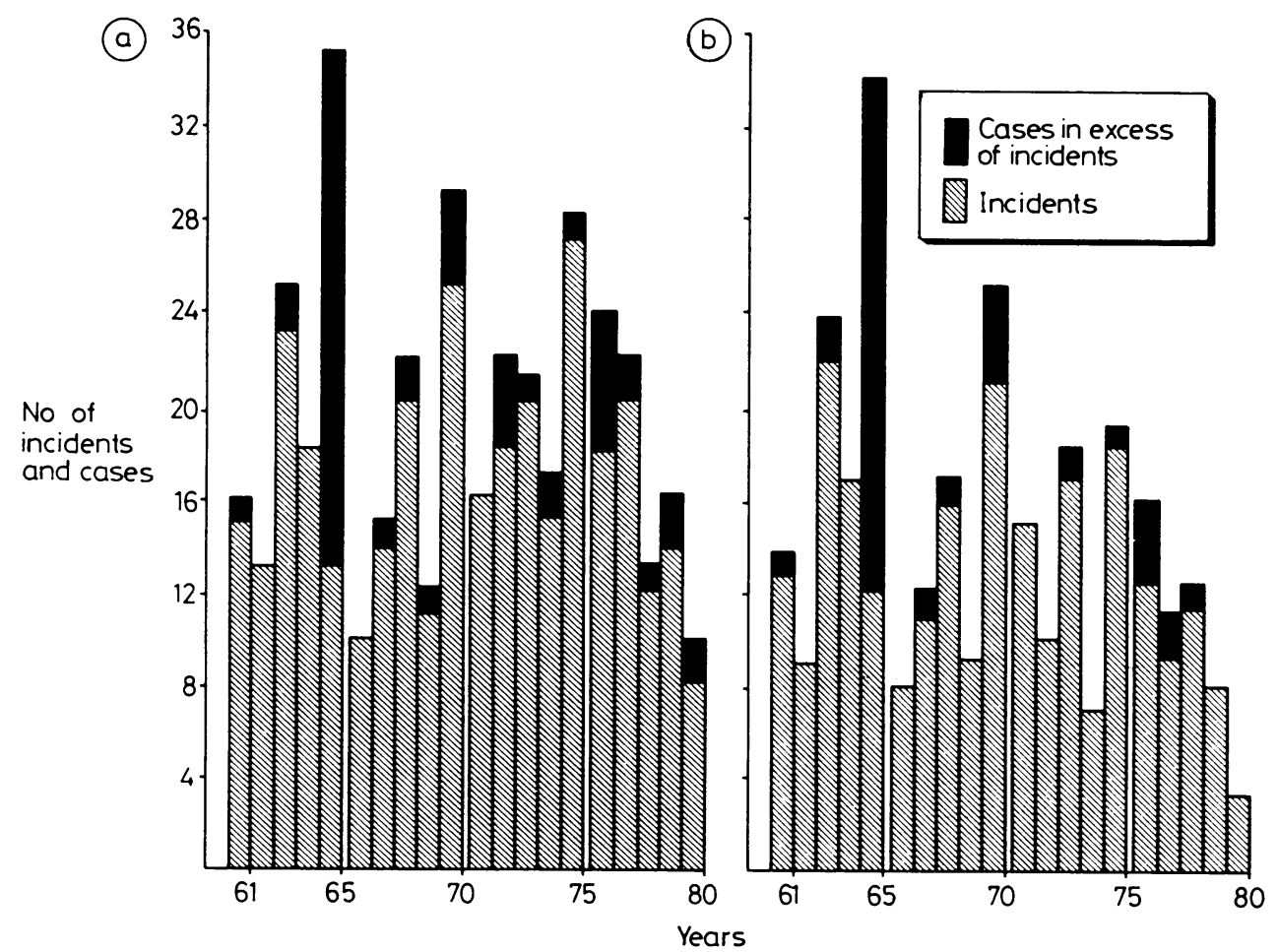

Fig 1 Number of incidents and cases a year of (a) all three solvents, and (b) trichloroethylene gassings, $1961-80$. 
cases occurring in any particular year varied from nine to 34 , the latter figure being swollen by one incident affecting 22 individuals; and the number of actual incidents for any given year throughout the period ranged from nine to 27 . The number of notifications a year showed no particular trend over the period studied (fig 1).

No case of 1-1-1 trichloroethane poisoning was reported before 1966 . Since then there have been a few cases each year, again with no particular trend.

\section{TOXIC EFFECTS}

Symptoms and signs were most commonly attributable to effects on the central nervous system. Gastrointestinal and respiratory symptoms were also quite common. Table 1 shows the frequency of the various symptoms and signs reported for each solvent.

\section{HEPATOTOXICITY}

Two of the five trichlorethylene poisonings resulted from ingestion, neither of which resulted in overt liver disease. In the other three cases one patient was reported to have abnormal bilirubin concentrations and another to have abnormal liver function tests with a tender right hypochondrium. Detailed biochemistry results were not available for either case. In the third case hepatic tenderness was the only positive finding. Hepatic dysfunction was mentioned in one case of perchlorethylene gassing on the basis of a very marginally raised SGPT in an otherwise asymptomatic 46 year old man. In none of the six cases was there sufficient evidence in the records to substantiate a clear diagnosis of hepatotoxicity.

\section{EFFECTS ON THE HEART}

The three cases where cardiac effects were postulated are described briefly below:

Case 1-A 43 year old man developed an irregular pulse after exposure to trichlorethylene and was admitted to hospital where his cardiac rhythm was found to have reverted to normal.

Case 2-A 47 year old man collapsed suddenly while exposed to trichlorethylene vapour, and the sudden nature of this collapse without preceding symptoms was considered by the investigating medical officer to be more likely to be due to cardiac dysrhythmia than narcosis.

Case 3-A 55 year old man was admitted to hospital after dizziness, chest tightness, and pain in the arm. Subsequent ECG examination showed no evidence of dysrhythmia and supported a diagnosis of myocardial ischaemia.

\section{DEATHS}

Of the 17 deaths, all were men, four being under 20 , including two cases of probable solvent abuse. The mean age for deaths was 35 years compared with a mean of $35 \cdot 3$ for all cases.

\section{SOLVENT ABUSE}

In nine case reports solvent abuse was specifically mentioned as a possible causative factor. Seven of these cases were in the 15-19 year age group.

\section{SEX}

All reported deaths were male. Sixty eight women were affected but whereas most men suffered sufficient severe exposure as to be rendered unconscious, under a quarter of the women lost consciousness (table 2).

\section{AGE}

When divided into five year age groups, the greatest number of cases occurred in the 15 to 19 group. In this group alone more incidents resulted in uncon-

Table 2 Gassings due to all solvents

\begin{tabular}{lcc}
\hline & $\begin{array}{l}\text { Unconscious } \\
\text { or fatal }\end{array}$ & $\begin{array}{l}\text { Consciousness } \\
\text { preserved }\end{array}$ \\
\hline Men: & & \\
$15-19$ & 41 & 22 \\
$\geqslant 20$ & 123 & 124 \\
All men & $169^{*}$ & $147^{*}$ \\
Women: & 7 & 3 \\
$15-19$ & 9 & 49 \\
$\geqslant 20$ & 9 & \\
\hline
\end{tabular}

${ }^{*}$ Ages were missing for six men.

\begin{tabular}{llll}
\hline & Trichlorethylene & Methyl chloroform & Perchlorethylene \\
\hline Total No of cases & 288 & 52 & 44 \\
Unconsciousness & 125 & 26 & 17 \\
Conscious with: & 128 & 18 & 22 \\
$\quad \begin{array}{l}\text { Central nervous system symptoms and signs } \\
\text { Gastrointestinal symptoms (nausea or vomiting) }\end{array}$ & 76 & 9 & 9 \\
$\begin{array}{l}\text { Respiratory symptoms (cough, breathlessness, chest } \\
\text { tightness) }\end{array}$ & 55 & 11 & 9 \\
$\begin{array}{l}\text { Symptoms or signs attributable to: } \\
\text { Hepatic effects }\end{array}$ & 5 & - & 1 \\
$\begin{array}{l}\text { Cardiac effects } \\
\text { Renal effects }\end{array}$ & - & - & - \\
\hline
\end{tabular}




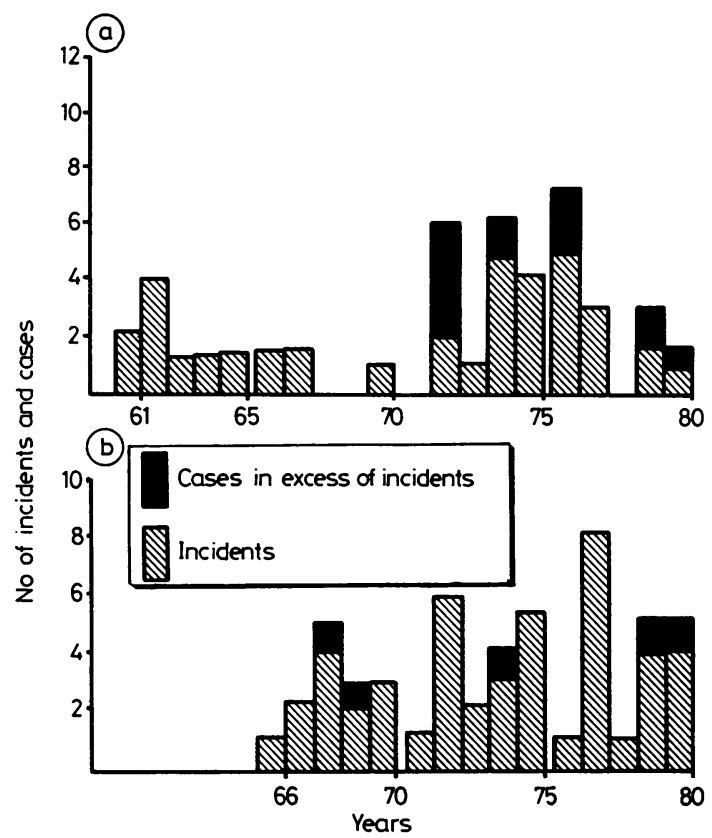

Fig 2 Number of incidents and cases of (a) perchlorethylene gassings and (b) 1-1-1 trichloroethane gassings, $1961-80$.

sciousness than did not (fig 2). The effect held true for both sexes. $2 \times 2$ contingency tables were constructed from table 2 relating degree of severity to age group and chi squared values calculated. For both sexes the proportion of unconsciousness or fatal cases was greater in the younger victims than in the older group. For men and women considered together $p=0.006$ for women $p=0.03$, and for men $p=0.06$.

\section{SOLVENTS}

Table 3 shows the number of men affected and rendered unconscious for each individual solvent.

\section{USE IN CONFINED SPACE}

Ten of the 14 deaths due to accidental exposure occurred in circumstances where regulations on entry into confined spaces were deemed to have been applicable.

\section{Discussion}

The nature of the basic data from which the analyses presented have been compiled is non-standardised. While similar report proformas were used for each case, these reports were completed over 20 years by many different physicians with varying interests and biases and under widely differing investigative cir- cumstances. Care was taken to avoid bias in the extraction of the information by taking the data at face value and by drawing up a priori groups of factors to be extracted. While we believe that the data were looked at with an open mind and without preconceived notions, the introduction of bias is still a possibility.

The data represent a large series of industrial solvent poisonings that is probably as comprehensive and representative of total industrial incidents in the United Kingdom as it is possible to achieve. Unfortunately, information is not available on the number of people occupationally exposed to these substances, and variation in the degree of use of these solvents cannot be taken into account. The figures do not show any trend of incidence with time. Without information on the actual amounts of these substances used and with so many other variables inherent in the data source, it is not possible adequately to discuss the question of changes with time. The relatively recent introduction of trichloroethane as an industrial solvent is evidenced by the lack of industrial poisonings reported before 1966 .

The clinical manifestations described and reported in the various incidents show that depression of the central nervous system and narcosis are the major toxic effects of these compounds. In two cases there is reasonably strong suspicion of a dysrhythmogenic effect but the evidence for hepatotoxicity seems much less clear; indeed, from these data it is difficult to see that these compounds produce a practical hepatotoxic threat in industry.

Cases of addiction certainly occurred but because of the difficulty of ascertaining the exact facts in many of these incidents, it is only where this occurs in obvious circumstances that sniffing or addiction can be definitively documented.

The preponderance of men and the relatively greater severity found in this group as compared with the women may be considered to reflect the differing sex distribution in various occupations in industry. Thus the relative non-affliction of women is most likely to be because few women are employed in occupations where exposure to these solvents appeared to be most hazardous - for example, maintenance of plant and entry into confined spaces.

Surveys of the labour force of Britain show that under $10 \%$ of the potential workforce is aged 16$19 .{ }^{16}$ That $19 \%$ of our cases were in the $15-19$ age group therefore seems to indicate a relative excess of cases in this group and is therefore cause for concern. When coupled with the relative increase in the number of more severe incidents, it would appear to provide good evidence that the younger age group is particularly vulnerable to solvent poisoning. One can speculate on the reasons for this but factors such 
Table 3 Men only

\begin{tabular}{|c|c|c|c|}
\hline Mode of use & Solvent & No of cases & Unconscious and fatal cases \\
\hline Operating degreasing baths & $\begin{array}{l}\text { Trichlorethylene } \\
\text { Perchlorethylene } \\
\text { 1-1-1 Trichloroethane }\end{array}$ & $\begin{array}{r}103 \\
0 \\
5\end{array}$ & $\begin{array}{l}39(38 \%) \\
0 \\
4(80 \%)\end{array}$ \\
\hline Maintaining or servicing degreasing baths & $\begin{array}{l}\text { Trichlorethylene } \\
\text { Perchlorethylene } \\
\text { 1-1-1 Trichloroethane }\end{array}$ & $\begin{array}{r}62 \\
1 \\
4\end{array}$ & $\begin{array}{c}38(61 \%) \\
1 \\
3(75 \%)\end{array}$ \\
\hline Use in portable cold form & $\begin{array}{l}\text { Trichlorethylene } \\
\text { Perchlorethylene } \\
\text { 1-1-1 Trichloroethane }\end{array}$ & $\begin{array}{r}37 \\
3 \\
33\end{array}$ & $\begin{array}{r}27(73 \%) \\
1(33 \%) \\
19(58 \%)\end{array}$ \\
\hline Dry cleaning & $\begin{array}{l}\text { Trichlorethylene } \\
\text { Perchlorethylene } \\
\text { 1-1-1 Trichloroethane }\end{array}$ & $\begin{array}{r}1 \\
17 \\
0\end{array}$ & $\begin{array}{l}1 \\
9 \\
0\end{array}$ \\
\hline Miscellaneous use & $\begin{array}{l}\text { Trichlorethylene } \\
\text { Perchlorethylene } \\
\text { 1-1-1 Trichloroethane }\end{array}$ & $\begin{array}{r}36 \\
10 \\
4\end{array}$ & $\begin{array}{r}19(53 \%) \\
4(40 \%) \\
2(50 \%)\end{array}$ \\
\hline All uses & $\begin{array}{l}\text { Trichlorethylene } \\
\text { Perchlorethylene } \\
\text { 1-1-1 Trichloroethane }\end{array}$ & $\begin{array}{r}239 \\
31 \\
46\end{array}$ & $\begin{array}{r}124(52 \%) \\
15(48 \%) \\
26(57 \%)\end{array}$ \\
\hline
\end{tabular}

as youthful exuberance, lack of experience, and possible predilection to sniffing solvents should be considered. In respect of the latter factor, however, it should be borne in mind that investigators may be more inclined to think of sniffing or addiction in this younger age group whereas the possibility might not be considered or raised when investigating similar incidents in those of more mature years. Nevertheless, that seven of the nine cases thought to be caused by deliberate self exposure were in the younger age group is evidence of the importance of this factor but does not numerically explain the excess of more severe cases found in this age group. Physiological differences could also be relevant factors.

The results in terms of number of cases per individual solvent probably mirror the relative use of the individual compounds. The relatively small number of cases attributed to perchlorethylene poisoning may at least be partly due to the fact that the use of perchlorethylene is largely confined to the dry cleaning industry, where the solvent is used in enclosed

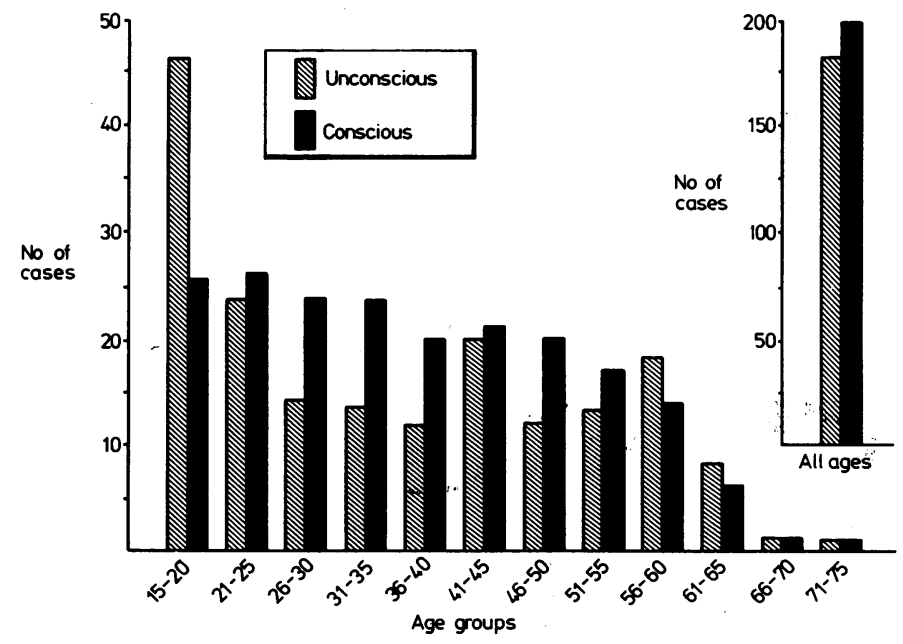

Fig 3 Number of conscious and unconscious (including fatal) cases from all three solvents in five year age groups, 1961-80. 
systems so that opportunity for human exposure is restricted. All gassing incidents associated with dry cleaning occurred in association either with faulty plant or during the maintenance of plant.

While the operating of degreasing baths accounted for the greatest number of cases found with any particular mode of use, two other modes of use-namely, the maintenance of such baths and the use of solvent in portable or cold form-produced at least as many severe or fatal cases. This, combined with the fact that 10 of 17 of the solvent deaths occurred because of use in confined spaces, shows the importance of circumstances of use when considering toxic effects of these solvents. Solvent in a portable and cold form may often be taken into poorly ventilated areas or confined spaces, and during the maintaining or servicing of degreasing baths, entry into tanks frequently occurs. Such circumstances clearly increase any potential solvent hazard.

\section{Conclusion}

From the data presented, the occurrence of industrial poisonings due to chlorinated hydrocarbons does not appear to have changed during 1961-80. These compounds clearly exert their greatest toxic effect by virtue of their narcotic properties whereas hepatotoxicity does not appear to be a major hazard. In occasional cases dysrhythmias resulting from hyperexcitability of myocardium may occur. There is good evidence that people in the younger age groups are relatively at greater risk of industrial poisoning with these compounds and that when such occurrences happen, they are more likely to be severe. For the three compounds considered, severity of toxic effects appeared to be more closely related to the mode of use than to the particular solvent used, and use of solvents in confined space is particularly hazardous. Supervisory staff should be constantly aware of the possibility of solvent abuse, and this factor should be borne in mind when selecting staff.
We would like to acknowledge the work of the various physicians investigating the many individual incidents whose reports form the basis of this paper.

This work formed part of a submission for the University of London MSc in Occupational Medicine by Dr TB McCarthy, for which he was sponsored by Arthur Guinness, Son and Co Ltd.

\section{Requests for reprints to RDJ.}

\section{References}

'Browning E. Toxic solvents: a review. $B r J$ Ind Med 1959;16:23-39.

${ }^{2}$ Hunter AR. Inhalation anaesthetic agents. $\mathrm{Br} J$ Anaesth $1962 ; 34: 224-8$.

${ }^{3}$ Willcox WH, Spilsbury BH, Legge TM. An outbreak of toxic jaundice of a new type amongst aeroplane workers. Medical Society's (of London) Transactions 1915;129-56.

4 Coyer HA. Tetrachlorethane poisoning. Industrial Medicine 1944;13:230-3.

s Léri A, Breitel. La Polynévrite chlorique. Bull Soc Med Hôp Paris 1922;46:1406-12.

- Geiger AJ. Cardiac dysrhythmias and syncope from therapeutic inhalation of chlorinated hydrocarbons. JAMA 1943;123: $141-4$.

${ }^{7}$ Hardin BL. Carbon tetrachloride poisoning: a review. Industrial Medicine and Surgery 1954;23:93-105.

Barnes CG, Ives J. ECG changes during trilene anaesthesia. Proc $R$ Soc Med 1944;37:528-32.

Ashe WF, Sailer S. Fatal uraemia following single exposure to carbon tetrachloride fumes. Ohio State Med J 1932;38:553-5.

${ }^{10} \mathrm{Kittleson} \mathrm{KD}$, Burden CW. Acute renal failure due to carbon tetrachloride poisoning. Quarterly Bulletin Northwestern University Medical School 1956;30:117-23.

"Steward RD. The toxicology of methyl chloroform. JOM 1963;5:259-62.

12 National Institute of Occupational Safety and Health. Criteria for a recommended standard .. . occupational exposure to tetrachlorethylene (perchlorethylene), 1976. (DHEW Publication No (NIOSH) 76-155.)

${ }^{13}$ Browning E. Toxicity of industrial organic solvents. (MRC report No 80.) London: Medical Research Council, 1953.

14 Browning E. Toxicity and metabolism of industrial solvents. Amsterdam: Elsevier, 1965.

is Factories Act 1961, Section 80. London HMSO, 1961.

${ }^{16}$ Labour Force Survey, London: HMSO, 1980. 